\title{
Effects of Used Bedding Straw and Drying it in Sunshine on Lying Behavior in Stable Horses
}

\author{
Masato AOYAMA ${ }^{1 *}$, Noriko YOSHIMURA ${ }^{1}$, Shoei SUGITA ${ }^{1}$ and Ryo KUSUNOSE ${ }^{2}$ \\ ${ }^{1}$ Faculty of Agriculture, Utsunomiya University, 350 Mine-machi, Utsunomiya-shi, Tochigi 321-8505, ${ }^{2}$ Equine \\ Research Institute, Japan Racing Association, 321-4 Tokami-cho, Utsunomiya-shi, Tochigi 320-0856, Japan
}

This study investigated the lying behavior of horses in the stable with used bedding material (rice straw) that was dried in sunshine. Six geldings were used in this study. Three types of straw were prepared: fresh straw that was not used as bedding materials before (New), used straw that was dried in sunshine for eight hours (UD), and used straw that was kept in a shaded area (U). Horses' behavior was observed during the night (16:30-5:30). Although there were no significant differences in the total duration of the recumbent position on three types of straw, four and three geldings lay more than 60 min in the stable on New and UD straw, respectively, whereas no geldings lay more than 47 min on U straw. Furthermore, short lying bouts (less than ten minutes) were seen three times in the stable with $U$ straw whereas such were never seen in the stable with New and UD straw. The water content of $U$ straw was significantly higher than in New and UD, and there was no difference between New and UD. The airborne ammonia (ANH3) concentration in the stable with $U$ straw was significantly higher than that in New straw, but there was no significant difference between $U D$ and U straw. In conclusion, horse's lying behavior was disturbed in the stable with used straw, but drying the used straw in sunshine can relieve this disturbance. Nevertheless, drying in sunshine was not enough to remove the urine ammonia completely from used straw, and this might be one of the causes of incomplete relief of the disturbance.

Key words: bedding straw, lying behavior, resting, reusing, stable environment

\author{
J. Equine Sci. \\ Vol. 15, No. 3 \\ pp. 67-73, 2004
}

Some materials, such as straw or wood chip, are usually putted into stables as beddings for horses. Previous reports indicate that the condition of bedding materials affect the stable environment [2, 5, 9-11], and consequently, can affect the health of horses. For example, the concentration of airborne dust, which can induce disease in the respiratory system [1,2], is higher in stables with straw than in those with woodshavings or paper [11]. In addition, the condition of bedding material can affect the stable environment even when using the same kind of material $[9,10]$. These previous reports indicate that horse owners have to pay attention to the condition of bedding materials for horses' health.

In Japan, rice straw is ordinarily used as the bedding material. Some horse keepers in Japan reuse the used

This article was accepted June 23, 2004

${ }^{*}$ Corresponding author. bedding straw that is dried in sunshine. The reuse of bedding straw seems to possess three advantages. Firstly, it would be useful from the economical point of view because horse owners can reduce the purchase of straw. Secondly, it would be useful from the ecological point of view because the waste produced from horse keeping can be reduced. And thirdly, since the transporting bedding straw would decrease, it might be possible to reduce the spread of pathogens carried by straw. Nevertheless, used bedding material contains horse feces and urine, which would induce a high water content of bedding and a high concentration of airborne ammonia (ANH3) in the stable [10]. Both of these situations will provide a horse with an uncomfortable environment. Furthermore, harmful microorganisms can increase in a stable with used bedding $[5,10]$. Drying the used bedding straw in sunshine seems to improve the condition of straw, but the effects of reused straw and the effects of drying it in 
sunshine have not been investigated. We have to know the effects of dried-reused straw on the stable environment and on the comfort of horses.

In cattle, the surfaces of the stall [8] and the housing designs [12] affect lying behavior, and its analysis can be a useful indicator for evaluating their environments. Although there are few reports indicating the effects of stable environments on horses' lying behavior, the stable environment must affect it, and its analysis is thought to be a good indicator for evaluating the stable environment, in other words, the comfort of horses. Therefore, to evaluate comfort in a stable with reused straw that was dried in sunshine, this study investigated behavior, especially the lying behavior of horses. We also examined the water content of the used straw and the ANH3 concentration in the stable with it.

\section{Materials and Methods}

\section{Animals}

Six geldings (four Thoroughbred and two AngloArabian, aged 10-20 years, 480-550 kg) were used in this study. They were kept in the Horse Riding Club of Utsunomiya University, which is located in Utsunomiyacity in Japan (latitude 36'3 N; longitude 139'5 E). The geldings were fed three times $(8: 30,12: 00$ and 16:30) a day. Each time the fodder consisted of $1 \mathrm{~kg}$ of timothy hay, $1 \mathrm{~kg}$ of hay cube (alfalfa hay), $700 \mathrm{~g}$ of barley (Tochigi Goudou Seibakusho, Tochigi, Japan), $500 \mathrm{~g}$ of wheat bran (Nippon Flour Mills Co. Ltd, Tokyo, Japan), $500 \mathrm{~g}$ of pelleted diet (Yushun; Nihon Nosan Co. Ltd, Yokohama, Japan), $10 \mathrm{~g}$ of salt (Nichien Co. Ltd, Tokyo, Japan) and $5 \mathrm{~g}$ of colloidal calcium carbonate (Colloical; Shiraishi Calcium Kaisha, Osaka, Japan). In addition, timothy hay was available at night (16:30-5:30), and water was always available throughout the day. They were trained for $90 \mathrm{~min}$ in the morning (5:30-7:00), and were left in the paddocks for nine hours (7:15-16:15) every day. Each gelding was in an individual stable from 16:30 to 5:30 the next day. The same person trained the same horse throughout the study.

\section{Bedding straw for experiment}

The rice straw was obtained from a neighboring farm and was used as bedding material. We prepared three types of straw for this experiment: 1) fresh straw which was not used as bedding material before (New), 2) straw that was used as bedding once and was dried in sunshine for eight hours (8:00-16:00) (Used and Dried; UD). This straw was upended at least once during drying, 3) straw that was used once and removed from the stable, and kept in plastic cases in a shaded area for eight hours (Used; U). Feces were removed from UD and U straw. The straw used only once was prepared as UD or U straw. For each horse, the straw that was used by himself was prepared as his own UD and $U$ straw. One gelding named Canute was not induced in the study with $\mathrm{U}$ straw because his left-rear unguis had light thrush. The bedding straw was put in the stable to make a $20 \mathrm{~cm}$ thick layer.

\section{Experimental Procedure}

This study was conducted between July and December in 2001: the observation of each of the six geldings was conducted on Aug 8-24, Sep 18-Oct 5, Oct 19-28, Nov 11-19, Nov 28-Dec 2 or Dec 14-22. At least eight days prior to the behavior observation, each horse was housed in an experimental stable $(3 \times 3 \times 3$ $\mathrm{m})$ to become accustomed. Each horse was trained and left in the paddock as usual during the experiment period. On the day of the first observation, one of the three types of materials was introduced into the stable, and the behavior of the horse was recorded. The behavior of the horse was recorded on just one night per type of straw. After a two to four day interval, another type of straw was introduced and the procedure was repeated. The order of the introduced straw type was based on the Latin square design. New straw was used as the bedding during the accustoming period and interval periods.

\section{Behavior observation}

The behavior of the horse was recorded from 16:30 to 5:30 the next day by a video camera on the ceiling. Ingestive behavior and lying behavior were observed by continuous recording. Pictures of lying behavior (sternal and lateral recumbency) were reported in previous studies $[4,6]$.

\section{Condition of the stable environment}

On the day of behavior observation, temperatures in the stable, water contents in the straw and ANH3 levels in the stable were measured at 16:30 (just before introducing the horses into the stable). Straw was sampled in a $70 \mathrm{~L}$ vinyl bag to measure its water content. Each type of straw was dried in an electric oven $\left(70^{\circ} \mathrm{C}, 24 \mathrm{hr}\right)$, and the water content was defined 
as the percentage of weight lost due to drying to the weight prior to drying. The ANH3 level in the stable was determined by using Pump Gas Sampling and Inspection Tubes (Gastec Corporation, Ayase, Japan). Since we did not have the apparatus for measuring ANH3 in the studies of the first three, ANH3 concentrations were measured only in the studies of the last three geldings.

\section{Data Analysis}

The total duration of recumbency, and the latency from the observation onset to the first recumbency were compared with Wilcoxon's matched pairs signed rank test (Wilcoxon's test) among three types of straw (data on Canute were not included in the comparing with U straw). The latencies for the geldings that did not lie down were regarded as $781 \mathrm{~min}$. The duration of each bout of lying down were compared with Fisher's exact probability test (Fisher's test). Water content of the straw and ANH3 levels were compared with one way analysis of variance (ANOVA) followed by Tukey's Studentized range test. $P$ values less than 0.05 were considered as significant.

\section{Results}

Feeding behavior: There were no differences in the duration of the period spent in feeding among the three types of straw (Fig. 1).

Lying behavior: The total duration of the lying varied between 0 and $156 \mathrm{~min}$ (Fig. 2A). There were one or two horses that did not lie down throughout the study in the stable with every type of straw. There were no significant differences in the average total duration of lying down between all types of straw (Fig. 2A), but no horses lay more than $47 \mathrm{~min}$ in the stable with U straw whereas four and three geldings, respectively, lay more than $60 \mathrm{~min}$ on New and UD straw. There were no differences in latency to the first recumbency among three types of straw (Fig. 2B). The histogram of the duration of each lying bout are shown in Fig. 2C. In the stable with New or UD straw, horses kept lying down longer than ten minutes when they had lain down once, but three lying bouts shorter than ten minutes were observed in the stable with $\mathrm{U}$. There was a significant difference in the distribution of the histogram between New and U $(\mathrm{P}<0.05$, Fisher's test $)$, and although it was not statistically significant, the distribution of the histogram of UD straw tended to differ from that of $U$

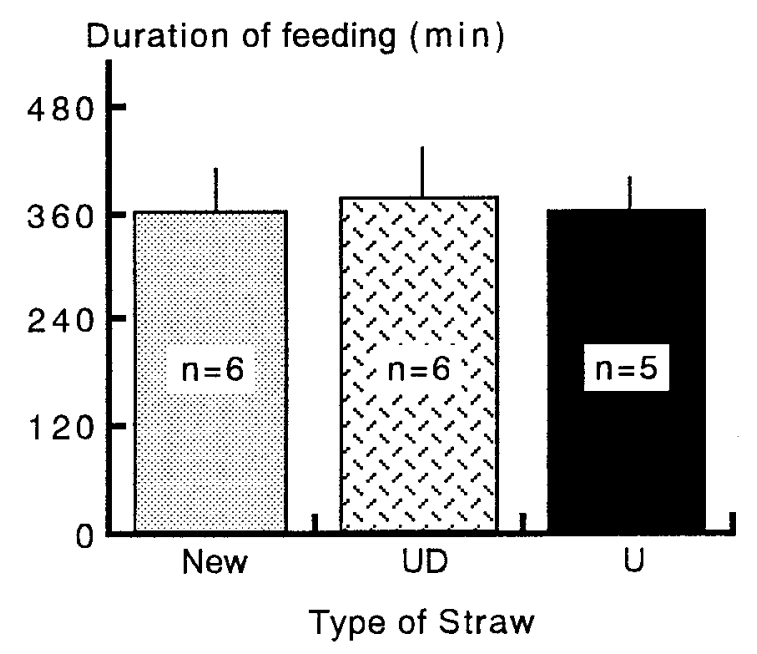

Fig. 1. The total durations of the periods spent in feeding stable horses with New, UD or U straw. The period of observation was $780 \mathrm{~min}(16: 30-5: 30)$. Each column represents the mean \pm SD for five or six geldings. Each number inside the column represents the sample size. New: fresh rice straw which was not used as bedding before, UD: used straw that was dried in sunshine for eight hours, U: used straw. See the text for detailed explanations of straw preparation.

straw $(\mathrm{P}=0.082)$.

Stable environments: Water content of U straw was significantly higher than in New and UD straw, and there was no difference between New and UD straw (Fig. 3A). The ANH3 level in the stable with U straw was significantly higher than that with New straw, but there was no significant difference between UD and U straw (Fig.3B). There was a significantly high correlation coefficient $(r=0.759, \mathrm{P}<0.05)$ between water content of straw and stable ANH3 levels (Fig. 3C). Although there were no significant differences, the proportions of the ANH3 level to the water content in UD and U straw were higher than that in New straw (Fig. 3D).

Effects of seasons: Seasonal changes in the stable temperature, water content in straw and total duration of the lying period are shown in Fig. 4. Temperature in the stable decreased gradually from August to December (Fig. 4A). Water content in New and $U$ straw did not show clear seasonal change (Fig. 4B), but those in UD straw were 10.4-11.6\% between August and October, but 16.3-22.8 \% between November and December. Total duration of lying down did not show a clear seasonal change (Fig. 4C). 

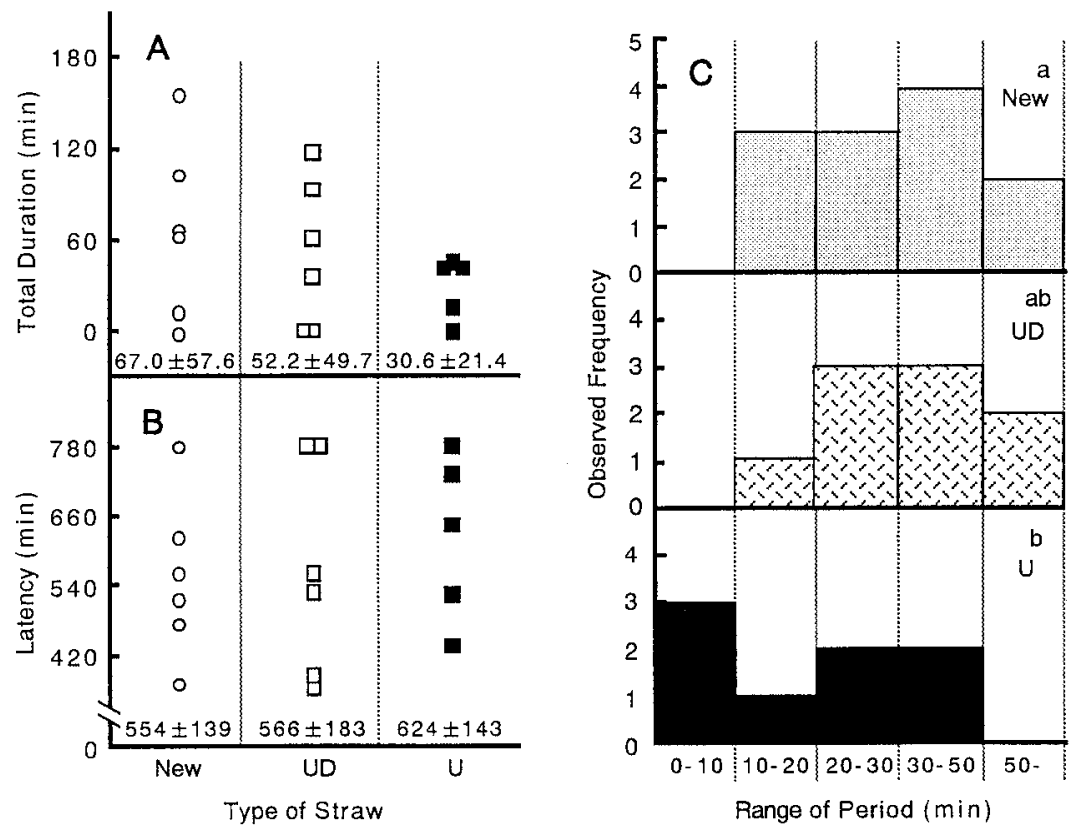

Fig. 2. Lying behavior of horses in a stable with New, UD or U straw. A: the total durations of the periods spent lying down, B: latencies from observation onset to the first recumbency, C: the histograms of lying bouts divided according to duration. The observed period was $780 \mathrm{~min}$ (16:30-5:30). Each point in panel A or B represents the result for each gelding, and each value on the bottom of each panel represents the mean \pm SD for five or six geldings. In panel B, the latencies for geldings that did not lie down throughout the observation are represented as 781 min. The frequencies of the lying bouts in panel $\mathrm{C}$ represent the total for five or six geldings. See the legend to Fig. 1 for the explanations of abbreviations. a, b: Significant differences are represented by not having the same letters (Fisher's test).
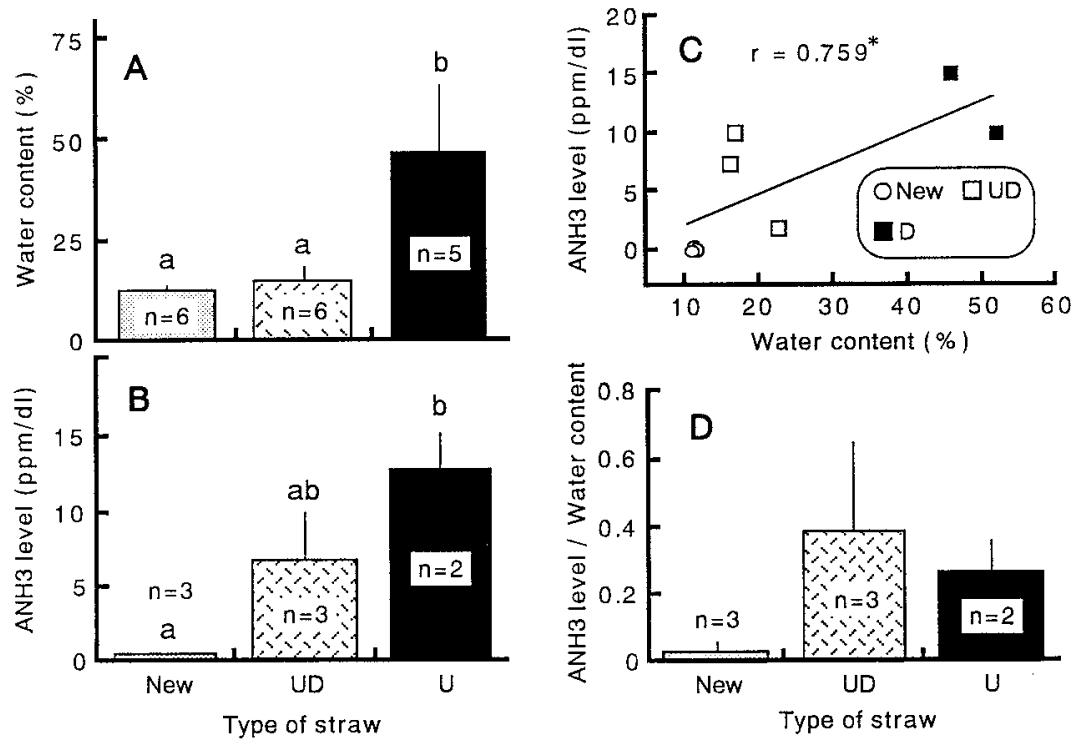

Fig. 3. The results for water content in New, UD and U straw, and airborne ammonia (ANH3) levels in the stable with them. A: water content in the straw, B: ANH3 levels in the stable, C: correlation between water content in straw and stable ANH3 level, D: the proportion of the stable ANH3 level to the straw water content. Each column represents the mean \pm SD. Each number inside or above the column represents the sample size. See the legend to Fig. 1 for the explanations of abbreviations. a, b: Significant differences are represented by not having the same letters (one-way ANOVA and Tukey's test). *: A significant correlation coefficient is seen. 


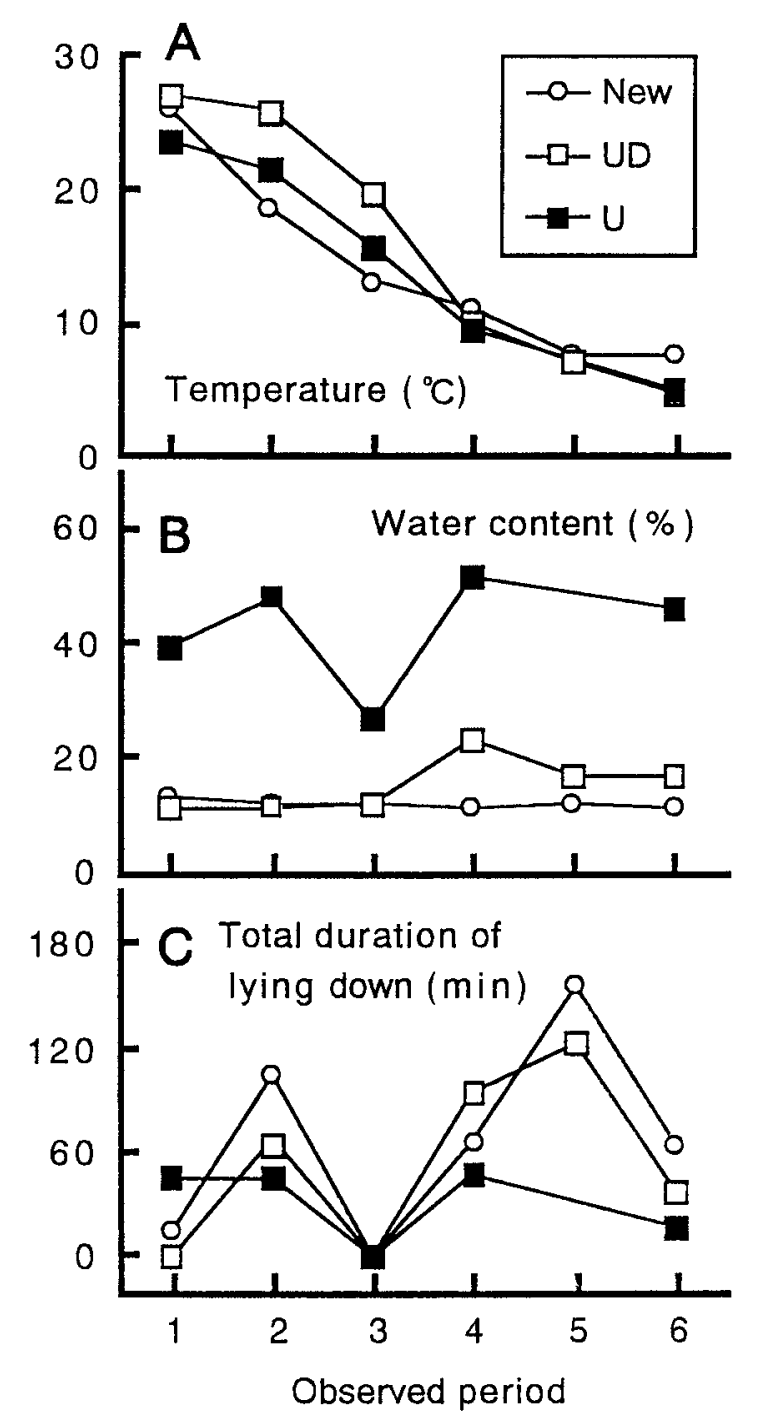

Fig. 4. Effects of seasons on the stable environments and lying behavior of stable horses with New, UD or U straw. A: temperatures in the stable on the observed days (measured at 16:30), B: water content in straw, C: total duration of lying down by each gelding. During each observed period, the same gelding was used. See the legend to Fig. 1 for the explanations of abbreviations. Each number on the vertical axis represents each observed period; 1:Aug 8-24, 2:Sep 18-Oct 5, 3:Oct 1928, 4:Nov 11-19, 5:Nov 28-Dec 2, 6:Dec 14-22.

\section{Discussions}

In this study, we examined the effects of reusing bedding straw and drying it in sunshine on the horses' behavior in the stable.
We did not measure the weight of timothy hay intaken in this study, therefore the actual effect of used bedding straw on the feeding motivation of stable horses is not clear, but, the duration of the period spent in feeding did not differ among the three types of straw. Bedding straw used for at least one night may not remarkably disturb the feeding behavior of horses.

There were no significant differences in the total duration of recumbency among the three types of bedding straw, but no horse lay down more than $47 \mathrm{~min}$ in the stable with $\mathrm{U}$ straw, whereas some horses lay more than 60 min with New straw. Furthermore, sometime horses stood up again immediately after they had lain on U straw whereas they kept lying for more than ten minutes every time on New straw. These results indicate that horses' lying behavior was disturbed by used straw. Horses' lying behavior in the stable with UD straw resembled that with New straw rather than with $\mathrm{U}$ straw. Although the total time lying on UD straw was slightly shorter than that on New straw, some horses lay more than $60 \mathrm{~min}$ on UD straw. Furthermore, no horse stood within ten minutes once they had lain on it. At least to some degree, drying used straw in sunshine can relieve its disturbing effect on horses' lying behavior.

We analyzed horses' lying behavior to evaluate their resting. Although a previous study indicates that horses spend less time lying down than other ungulate domestic animals [4], and analysis of electroencephalograms or electrocorticograms indicates that horses drowse and sleep (slow wave sleep) even while standing $[3,4]$. In this study, some geldings did not lie down or lay only for short periods (not longer than $15 \mathrm{~min}$ ) even in a stable with New or UD straw. In this study, the lying behavior of each horse might depend on the temperament of individual horses because there was a high positive correlation $(\mathrm{r}=0.88)$ in the total duration of lying in a stable with New and UD straw. Therefore, the disturbance of horses' lying behavior may not necessarily mean disturbance of their resting, at least for horses rarely lie down. Nevertheless, even the geldings that lay rarely in this study lay sometime in their own stable (personal observations: data not shown). And, previous reports indicate that rapid eye movement (REM) sleep was observed only during recumbency in horses [3, 4]. Therefore, it must be necessary for all horses to lie down sometime, and resting while standing cannot be exactly the same as resting while lying down. Disturbing horses' lying behavior continuously can 
disturb their resting, and consequently can negatively affect their health even for horses rarely lie down.

$\mathrm{U}$ straw had remarkably higher water content than New and UD straw, and that in UD straw was almost the same as that in New straw. This indicates that water content in straw is increased by using it as bedding, similarly to the previous report [10], but it can be restored to the level of New straw by drying in sunshine for eight hours. The relief of the lying behavior disturbance by drying used straw may be partially due to the reduction in its water content. In addition, drying used straw in sunshine seems to be important for horses' health because keeping a horse in a stable with wet straw can cause thrush. As for the water content, only drying used straw in sunshine may be enough to restore it to that in New straw.

Seasons seemed to affect the efficiency of drying used straw. The water content of UD straw increased slightly between late autumn and winter (NovemberDecember) compared with that between summer and early autumn (August-October). The relatively high water content of UD straw during late autumn-winter is thought to be the result of the low temperature during this season. In order to remove the water from used straw completely so that it is the same as in New straw, we have to dry it for more than eight hours, otherwise, we may have to upend it frequently. On the other hand, horses' lying behavior in a stable with UD straw did not seem to be disturbed more remarkably in winter than in summer. The differences in the total durations of lying in the stable with UD and U straw from those in New straw were calculated, but there were no clear seasonal changes in them. Drying used straw to nearly $20 \%$ water content may be enough, and removing more water (to nearly $10 \%$ ) may not be so effective for relieving the disturbance of horses' lying behavior.

The ANH3 concentration in a stable with $\mathrm{U}$ straw was significantly higher than that with New straw. But, unlike water content, the ANH3 concentration in a stable with UD straw was about a middle value between New and U straw, and it did not differ from either New or $\mathrm{U}$. The major cause of high water content in U straw must be horses' urine, because there was high positive correlation between water content in the straw and the ANH3 level in the stable. Nevertheless, although it was not statistically significant, the proportion of the stable ANH3 level to the water content in UD was about 15 times higher than that in New. This indicates that some urine ammonia may be left in the used straw even if the urine water is removed to the same level as New straw. The ammonia remaining in the used straw might be one of the reasons why horses did not lay on UD straw as in the same way as on New. We might have to pay attention to remove ammonia from used straw. Sweeny et al. reported that sodium bisulfate decrease the ANH3 level in the stable [7]. Applying some chemical substances, such as sodium bisulfate, may be useful when these were combined with drying the straw. Nevertheless, we measured AHN3 levels in the stable with UD straw only three times, and the effect of seasons on the ANH3 level in the stable with UD straw is not clear. Further studies are required to reveal more clearly the effect of drying the used straw on the AHN3 level in a stable where it is used.

In conclusion, horses' lying behavior is disturbed in a stable with used straw, but this disturbance is relieved to some degree by drying the used straw in sunshine. But this relief due to drying is not enough to completely restore used straw to new straw condition. One of the reasons for this incomplete relief by drying may be the urine ammonia left in the straw.

\section{Acknowledgments}

We are grateful to the staff members of the Horse Riding Club of Utsunomiya University for their technical help and kindness. This study was partially supported by the Grant Aid for Young Scientists from Utsunomiya University (2001).

\section{References}

1. Clarke, A.F. 1993. Stable dust—threshold limiting values, exposures variables and host risk factors. Equine Vet. J. 25: 172-174.

2. Clarke, A.F. and Madelin, T. 1987. Technique for assessing respiratory health hazards from hay and other source materials. Equine Vet. J. 19: 442-447.

3. Dallaire, A. and Ruckebusch, Y. 1974. Sleep and wakefulness in the housed pony under different dietary conditions. Can. J. Comp. Med. 38: 65-71.

4. Houpt, K.A. 1998. Domestic animal behavior for veterinarians and animal scientists. Third edition. pp. 83-109. Iowa State University Press, Ames.

5. Kosuge, J., Goto, Y., Shinjo, T., Anzai, T., and Takatori, K. 2000. Detection of Emericella nidulans from bedding materials in horse breeding environment and its significance as a 
causative agent of guttural pouch mycosis in horses. Jpn. J. Med. Mycol. 41: 251-256 (in Japanese).

6. Littlejohn, A. and Munro, R. 1972. Equine recumbency. Vet. Rec. 90: 83-85.

7. Sweeney, C.R., McDonnell, S., Habecker, P.L., and Russell, G.E. 1996. Effect of sodium bisulfate on ammonia levels, fly population, and manure $\mathrm{pH}$ in a horse barn. AAEP Proceedings 42: 306-307.

8. Tucker, C.B., Weary D.M., and Fraser D. 2003. Effects of three types of free-stall surfaces on preferences and stall usage by dairy cows. J. Dairy Sci. 86: 521-529.

9. Vandenput, S., Istasse, L., Nicks, B., and Lekeux, P. 1997. Airborne dust and aeroallergen concentrations in different sources of feed and bedding for horses. Vet. Q. 19: 154-158.

10. Ward, P.L., Wohlt, J.E., and Katz, S.E. 2001. Chemical, physical, and environmental properties of pelleted newspaper compared to wheat straw and wood shavings as bedding for horses. J. Anim. Sci. 79: 1359-1369.

11. Webster, A.J., Clarke, A.F., Madelin, T.M., and Wathes, C.M. 1987. Air hygiene in stables. 1: Effects of stable design, ventilation and management on the concentration of respirable dust. Equine Vet. J. 19: 448-453.

12. Wilson, L.L., Terosky, T.L., Stull, C.L., and Stricklin, W.R. 1999. Effects of individual housing design and size on behavior and stress indicators of special-fed Holstein veal calves. J. Anim. Sci. 77: 1341-1347. 